\title{
Successful transition to groundwork combat during Junior and Senior Judo World
}

\section{Championships}

Silvana Nagai, Monica Yuri Takito, Michel Calmet, Emanuela Pierantozzi, Emerson

Franchini

\begin{abstract}
Judo is a grappling combat sport in which victory can be obtained in standing or in ground positions. One consequence is a special phase between these two phases, denominated "transition". Previous studies suggested that eight basic positions of the athlete being attacked should be investigated: turtle, supine, prone, half-guard, beside, guard, standing and seated. However, few studies addressed the transition phase in judo matches. The main goal of the present study was to describe the successful transition phases in a high-level judo competition (World Championship) to determine the type of transition and their rhythms (i.e., time spent by the scoring athletes) mostly used by these athletes. Our sample was based on the Junior and Senior, male and females, Judo World Championships 2017. Transition phases $(\mathrm{n}=373)$ that resulted in a score during the Junior $(n=179)$ and Senior $(n=194)$ were analyzed. The main findings of this study indicated an immediate link between standing and groundwork actions observed in almost half of the occurrences. Most of the scoring actions $(\sim 75 \%)$ were achieved through an osae-komi-waza (immobilization techniques), and these actions were executed mainly when the match was tied $(\sim 71 \%)$. No significant differences were observed between sex and age groups concerning type of techniques and body position. The different types of transitions were used similarly along the competition phases, indicating that athletes need to be able to cope with different situations in the transition phase to be successful.
\end{abstract}

Keywords: time-motion analysis; performance; competition; technique. 


\section{Introduction}

Judo is a grappling combat sport disputed in seven weight categories for each sex, and in different age categories. During an official judo match, athletes can score using the following techniques: throwing techniques (nage-waza); immobilization techniques (osaewaza); elbow lock joint techniques (kansetsu-waza); strangle techniques (shime-waza) During official judo competition, the nage-waza are executed in the standing position or tachi-waza), whereas all other groups of techniques are executed during groundwork combat (ne-waza) (International Judo Federation, 2018).

In the last two decades, there was an increase in the interest of performance analysis of judo matches, including studies directed to provide precise information about the time-motion of actions executed (Castarlenas \& Planas, 1997; Marcon, Franchini, Jardim, \& Neto, 2010), the most commonly performed techniques (Adam, Smaruj, \& Tyskowski, 2011), the direction of attacks of these techniques and its association to success (Calmet \& Ahmaidi, 2004; Franchini, Sterkowicz, Meira, Gomes, \& Tani, 2008), the techniques composing the system of attacks of judo athletes (Calmet, Trezel, \& Ahmaidi, 2006), the relevance of grip dispute (Calmet, Miarka, \& Franchini, 2010; Courel, Femia, Stankovic, Franchini, \& Escobar-Molina, 2014), the influence of penalties on contest outcome (Escobar-Molina, Courel, Franchini, Femia, \& Stankovic, 2014), and integrative approaches to verify the factors contributing to the match result (Miarka, Branco, Vecchio, Camey, \& Franchini, 2015). However, few studies focused on the ne-waza (Weers, 1997) or the transition from tachi-waza to ne-waza (Roux, 1990; Weers, 1996; Pierantozzi, Calmet, \& Franchini, 2016; Pierantozzi, Calmet, \& Franchini, 2017). The initial analysis from Roux (1990) reported that transitions started mainly after the opponent blocked an attack (50.7\%), after escapes (28.4\%), after throws (18.1\%), and after a counter-attack $(2.8 \%)$, but that $42.7 \%$ situations considered as favorable to continue in ne-waza were unexploited. Using a similar approach, Weers (1996) 
demonstrated that $30.3 \%$ of the situations in ne-waza were controlled by the athletes who attacked in tachi-waza, $28.7 \%$ were controlled by those who were attacked in tachi-waza, while $41.0 \%$ of the situations resulted in no control by any athlete in ne-waza. Posterior analysis from Pierantozzi et al. (2016) indicated that only $27 \%$ of the transition opportunities resulted in a sequence of combat in ne-waza, even though eight transition per match occurred. However, a subsequent analysis of the same authors (Pierantozzi et al., 2017) indicated that $7 \%$ of the transitions resulted in ippon and $11 \%$ in wazari. Thus, this phase can be considered very important for the contest outcome. However, these studies did not compare sexes, age groups, moment of the match or competition phase, which could provide relevant information to improve the training process for specific groups, and the strategy during specific moments of the match or competition phase. Therefore, the main goal of the present study was to describe the successful transition phases in a high-level judo competition (World Championship) to determine the type of transition mostly used by these athletes. Additionally, our study aimed to compare the types of transition between Junior and Senior, male and female judo athletes, minute of match and competition phase. As the transition phase is quite relevant to score, the main hypotheses of the present investigation were that most of these actions would occur when the match was tied, but evenly distributed across the minutes of match and competition phases. Due to the reduction of immobilization time to score a wazaari (now a waza-ari is achieved when an immobilization is applied for 10s) most of the scores in the groundwork would be composed by osae-komi-waza. Considering that a short time between successive actions is a key element to become less predictable, immediate link between standing and groundwork actions would predominate. However, no significant difference would be observed between sex and age groups.

\section{Material and Methods}




\section{Participants}

All transition phases $(n=373)$ that resulted in a score during the Junior $(n=179)$ and Senior $(\mathrm{n}=194)$ Judo World Championships were considered in the present study, except for the Junior males under $55 \mathrm{~kg}$ and females under $44 \mathrm{~kg}$, as these categories are not disputed for the Seniors. This study was approved by the local research ethics committee $(62743516.7 .0000 .5391)$

\section{Design}

This is a cross-sectional study, analyzing high-level judo matches from both male and female, Junior and Senior, judo athletes who took part in the World Championship for their respective classification. All standing to groundwork combat transition phases that resulted in a score was analyzed.

\section{Match analysis}

The determination of the dependent variables in the present study followed the recommendations by Pierantozzi et al. (2016), Pierantozzi et al. (2017), Roux (1990) and Weers (1996), and the validated procedures from Miarka et al. (2011).

Briefly, a spreadsheet was developed in excel for data collection, containing the following columns: (A) sex (male, female); (B) weight category (numbered from 1 to 7); (C) age group (junior or senior); (D) phase (eliminatory, quarterfinals, semifinals, repechage, bronze and finals); (E) transition rhythm, in which was informed if the athlete performed the groundwork technique immediately after the throwing technique execution, if there was a consecutive link or if a progression in the ground. Specifically, the following definitions were used: Immediate transitions: when the athlete dominated the opponent, immediately after contact with the ground, without loss of control, although allowing some time lapse (shorter than $5 \mathrm{~s}$ ), especially when applying shime-waza or kansetsu-waza; Consecutive transitions: those where 
there could have been some loss of the athlete's control after contact with the ground, but that worked quickly and efficiently in ne-waza, in a time lapse between 5 and $7 \mathrm{~s}$ to control the opponent; Progressive transitions: when the control happened after some time lapse (more than $7 \mathrm{~s}$ ), after the athlete had to work on the ground, disputing the movements to reach his/her goal; (F) type of technique, where it was specified whether the score was obtained by osaekomi-waza, kansetsu-waza or shime-waza; $(G)$ uke's position at the time of transition (turtle, supine, prone, half-guard, beside, guard, standing and seated); $(\mathrm{H})$ the combat status, whether it was tied, whether the tori was winning or losing at the time of transition; and (I) the moment of the fight, in minutes.

Then, an analysis of all fights of the Junior and Senior World Championships was carried out, using official videos of the International Judo Federation, available on the institution's website (www.judobase.org), to identify those who had punctuated transitions resulting from the application of katame-waza techniques (osae-komi-waza, shime-waza or kansetsu-waza). After determining these occurrences, each sequence resulting from these scores was analysed to determine the actions involved.

\section{Statistical analysis}

The distribution of dependent variables was determined and percentages for each one was presented in relation to independent variables. Chi-square $\left(\chi^{2}\right)$ tests were utilised to verify any association between technique actions and sex, age, and phase in the competition followed by Cramer's - V effect size for the main comparisons. Time are presented as mean and standard deviation and t-test was utilised to compare between sex and age groups. As normality was not confirmed by the Shapiro-Wilk test, a Mann-Whitney U test was used to compare sex and age, and phase. Time was transformed in an ordinal variable. Significance level was set at 5\%. Data were analysed using the IBM SPSS (version 23, IBM Corp., Armonk, NY, USA). 


\section{Results}

Table 1 presents the distribution (percentage) of transition actions that resulted in scores for Junior and Senior, female and male, judo athletes taking part in the World Judo Championship. 
Table 1: Distribution (percentage) of rhythm, type of technique, uke body position and match status during transition actions performed in Junior and Senior, male and female, 2017 Judo World Championships.

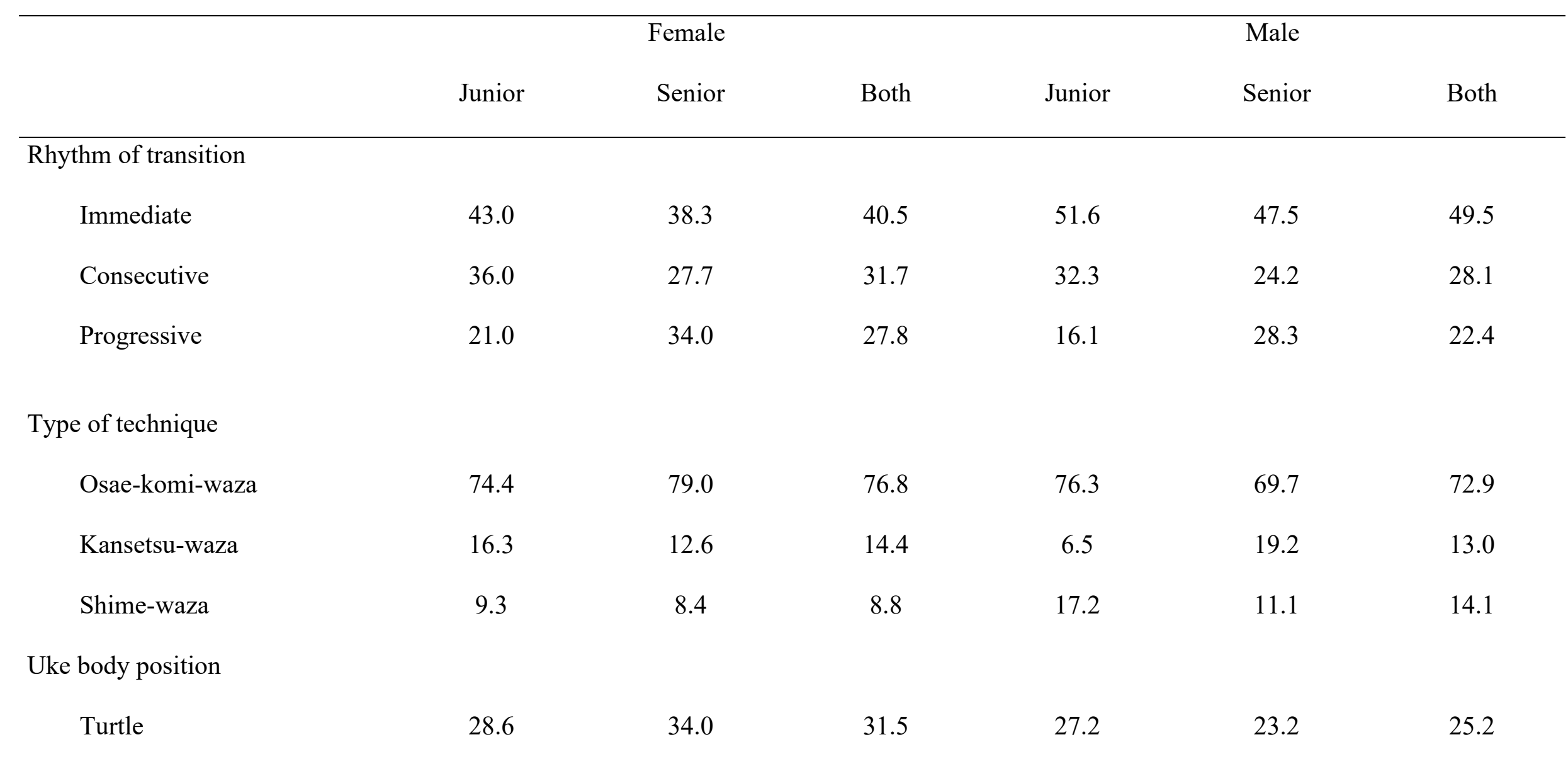


Supine

Prone

Half-guard

Beside

Guard

Standing

Seated

Status

Tied
Winning
Losing

Moment (minutes)
1
2
3

33.3

20.2

7.1

7.1

2.4

1.3

73.3

20.9

5.8

22.0

27.3

23.4
27.7

25.5

7.4

1.1

4.3

3.4

0.6

0.6

30.3

23.0

7.3

3.9

$-$

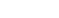

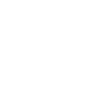

81.1

77.3

16.6

6.1

6.3

12.6

2.6

.

6.1

12.9

17.1

28.8

30.1

28.0

25.9
45.7

38.4

17.4

4.3

2.1

3.3

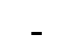

2.1

1.0

20.2

12.1

2.0

1.0

1.0

0.5

41.9

8.4

2.1

2.1

.0

$\begin{array}{lll}65.6 & 63.6 & 64.6\end{array}$

28.0

34.3

31.3

6.4

2.1

4.1

8.9

10.6

9.8

22.2

30.9

26.6

26.7

19.1

22.8 
$4+$

27.3

29.0

28.2

42.2

39.4

40.8

osae-komi-waza $=$ immobilization techniques; kansetsu-waza $=$ joint lock techniques; shime-waza $=$ strangle techniques; uke $=$ athletes receiving the technique. 
No significant associations between sex and body position $\left(\chi^{2}=9.07, p=0.248\right.$, Cramer's $\mathrm{V}=0.157)$, sex and rhythm of transition $\left(\chi^{2}=3.11, \mathrm{p}=0.212\right.$, Cramer's V $\left.=0.091\right)$ or between sex and technique executed $\left(\chi^{2}=2.52, \mathrm{p}=0.284\right.$, Cramer's $\left.\mathrm{V}=0.082\right)$ were found. There was a significant association between match status and $\operatorname{sex}\left(\chi^{2}=11.129, \mathrm{p}=\right.$ 0.004, Cramer's $\mathrm{V}=0.173$ ), most frequently for female than for male when the match was tied in the Senior group $\left(\chi^{2}=13.845, p=0.001\right.$, Cramer's $\left.V=0.267\right)$, but not for the Junior $\left(\chi^{2}=1.306, \mathrm{p}=0.520\right.$, Cramer's $\left.\mathrm{V}=0.085\right)$. Additionally, the time when these actions occurred $($ females $=136 \pm 74 ;$ males $=155 \pm 71)$ differ between sexes $(\mathrm{t}=-2.667 ; \mathrm{p}=0.008)$. No significant associations between age and body position $\left(\chi^{2}=8.49, \mathrm{p}=0.292\right.$, Cramer's V $=0.150)$, or between age and match status $\left(\chi^{2}=0.886, \mathrm{p}=0.642\right.$, Cramer's $\left.\mathrm{V}=0.049\right)$ were found. Additionally, time when these actions occurred (Junior $=147 \pm 74 \mathrm{~s}$; Senior $=145 \pm$ $69 \mathrm{~s})$ did not differ between age groups $(\mathrm{t}=0.352 ; \mathrm{p}=0.725)$. No association was found between age and technique executed for females $\left(\chi^{2}=2.65, \mathrm{p}=0.266\right.$, Cramer's $\left.\mathrm{V}=0.084\right)$. However, there was an association between technique executed and age for males $\left(\chi^{2}=7.534\right.$, $\mathrm{p}=0.023$, Cramer's $\mathrm{V}=0.198)$. An association of age and rhythm of transition $\left(\chi^{2}=8.44, \mathrm{p}\right.$ $=0.015$, Cramer's $\mathrm{V}=0.151$ ) was found when sex was grouped, with male doing more frequently progressive transition than female.

Eliminatory and repechage matches were compared to medal matches, but no association was found between competition phase and body position during $\left(\chi^{2}=4.42, p=\right.$ 0.731, Cramer's V $=0.109$ ): supine (Eliminatory $=36.1 \%$; Medal $=38.5 \%$ ), turtle $($ Eliminatory $=28.2 \% ;$ Medal $=28.2 \%)$, prone $($ Eliminatory $=20.0 \%$; Medal $=28.2 \%)$, halfguard $($ Eliminatory $=8.5 \%$; Medal $=2.6 \%)$, beside $($ Eliminatory $=3.0 \%$; Medal $=2.6 \%)$, guard $($ Eliminatory $=3.0 \%$; Medal $=0.0 \%)$, standing $($ Eliminatory $=0.6 \%$; Medal $=0.0 \%)$, and seated $($ Eliminatory $=0.6 \%$; Medal $=0.0 \%$ ). Competition phase was not associated with 
rhythm of transition $\left(\chi^{2}=3.49, \mathrm{p}=0.175\right.$, Cramer's $\left.\mathrm{V}=0.097\right)$ : immediate (Eliminatory $=$ $44.1 \%$; Medal $=53.8 \%)$, consecutive $($ Eliminatory $=29.4 \%$; Medal $=33.3 \%)$, and progressive (Eliminatory $=26.4 \%$; Medal $=12.8 \%$ ). Additionally, competition phase was not associated with type of techniques $\left(\chi^{2}=3.60, p=0.165\right.$, Cramer's $\left.V=0.098\right)$ : osae-komi-waza $($ Eliminatory $=75.4 \% ;$ Medal $=69.2 \%)$, kansetsu-waza $($ Eliminatory $=14.1 \% ;$ Medal $=$ $10.3 \%$ ), and shime-waza (Eliminatory $=10.5 \%$; Medal $=20.5 \%$ ). As well, competition phase was not associated with status of the match $\left(\chi^{2}=0.03, p=0.987\right.$, Cramer's V $\left.=0.008\right)$ : tied $($ Eliminatory $=70.7 \% ;$ Medal $=71.8 \%)$, winnng $($ Eliminatory $=24.3 \% ;$ Medal $=23.1 \%)$, and losing (Eliminatory $=5.1 \%$; Medal $=5.1 \%$ ). The time when these actions occurred also did not differ between competition phases (Eliminatory $=145 \pm 71 \mathrm{~s}$; Medal $=154 \pm 75 \mathrm{~s} ; \mathrm{t}=$ $0.794 ; p=0.428)$

No association was found between competition phase and body position $\left(\chi^{2}=4.42, p\right.$ $=0.731$, Cramer's $\mathrm{V}=0.109)$. Competition phase was not associated with rhythm of transition $\left(\chi^{2}=3.49, \mathrm{p}=0.175\right.$, Cramer's $\left.\mathrm{V}=0.097\right)$. Additionally, competition phase was not associated with type of techniques $\left(\chi^{2}=3.60, \mathrm{p}=0.165\right.$, Cramer's $\mathrm{V}=0.098$. As well, competition phase was not associated with status of the match $\left(\chi^{2}=0.03, p=0.987\right.$, Cramer's $\mathrm{V}=0.008)$. The time when these actions occurred also did not differ between competition phases.

There was a significant association between sex and moment (as a categorical variable $),\left(\chi^{2}=8.01, \mathrm{p}=0.046\right.$, Cramer's $\left.\mathrm{V}=0.150\right)$, with distribution increasing at the end (3-4 minutes) for male Junior $\left(\chi^{2}=8.006, p=0.045\right.$, Cramer's $\left.\mathrm{V}=0.220\right)$, but not for Senior $\left(\chi^{2}=3.21, \mathrm{p}=0.360\right.$, Cramer's $\left.\mathrm{V}=0.131\right)$.

When all factors were grouped, the five main transition positions that resulted in scores were supine $(35.9 \%)$, turtle $(27.9 \%)$, prone $(20.6 \%)$, half-guard $(7.8 \%)$ and lateral $(2.9 \%)$. In terms of rhythm of transition, $45 \%$ of situations were conducted immediately after 
the standing action, $29.8 \%$ were executed consecutively and $24 \%$ were performed progressively. The scoring techniques in the groundwork were mainly osae-komi-waza (74.8\%), followed by kansetsu-waza $(13.7 \%)$ and shime-waza (11.5\%). These actions occurred at $146 \pm 71 \mathrm{~s}$ of the match. These actions were executed mainly when the match was tied $(70.8 \%)$ or by the athlete winning the match $(24.1 \%)$, and only $5.1 \%$ were executed by the athlete losing the match.

Among all the transitions scored, $67.3 \%$ were performed by the athlete who attacked in tachi-waza. Of these, in $54.6 \%$ the athlete maintained the control and made the transition immediately; $22.3 \%$ consecutively and $23.1 \%$ progressively. The athletes who were attacked in tachi-waza performed only $31.1 \%$ of the scoring transitions. Of these, $26.7 \%$ occurred immediately, $45.7 \%$ consecutively and 27.6 progressively.

\section{Discussion}

The main findings of this study indicated partially confirmed our initial hypothesis. Specifically, an immediate link between standing and groundwork actions was observed in almost half of the occurrences, most of the scoring actions were achieved through an osaekomi-waza $(\sim 75 \%)$, and these actions were executed mainly when the match was tied $(\sim 71 \%)$. Moreover, no significant difference was observed between sex and age concerning type of techniques and body position. Conversely, males used more frequently immediate transition than females. Females more often used transition in tied matches than males for the Senior group, and females used transitions in a short period of the match compared to males. The different types of transitions were used similarly along the competition phases, indicating that athletes need to be able to cope with different situations in the transition phase to be successful.

The immediate link between standing and groundwork actions observed in almost half of the scoring actions demonstrates that the opportunity occurs in the transition phase, as 
previously reported by Weers (1996). This can be related to the fact that when the athlete being attacked stabilizes his/her position it is harder to find a gap to explore and execute some groundwork techniques. For instance, Kashiwazaki (2004) strongly recommended that scoring during groundwork combat depends of finding spaces to insert legs and/or arms, and this task is easier when the opponent is moving compared to when he/she is in a stable position. Thus, the large displacement resulting from the plane change (i.e., standing position to ground position) is the optimal situation to find spaces and control the opponent. Additionally, the judo rules determine that when groundwork combat has no continuity the match should be interrupted and restarted in the standing position. Thus, a shorter action is more likely to be successful than actions demanding more complex and longer sequences of movements (Pierantozzi et al., 2016). Another possibility is that situations where the athlete being attacked in the standing position are less explored during the formation period and during high-level training sessions and, consequently, athletes do not cope well with these situations (Roux, 1990).

Most of the transition scoring actions were executed mainly when the match was tied $(\sim 71 \%)$, which can be explained by the fact that both athletes are exploring actions and exposing themselves. This phase is characterized by a combination of vulnerability and full attention to any opportunity to score. Conversely, when one athlete is winning it is common that a defensive posture is adopted, avoiding the exposition to risky situations while taking the risk of receiving penalties (Balafoutas et al., 2013; Calmet et al., 2017a; Calmet et al., 2017b; Escobar-Molina et al., 2014). This can also explain why rarely the athlete losing the match score in the groundwork combat.

The predominance of groundwork scoring actions using osae-komi-waza confirmed our initial hypothesis that the reduction of immobilization time would result in a higher 
number of scores via these techniques. Hence, with shorter time to escape the immobilization the athlete caught in this technique would have a smaller opportunity to avoid being scored.

The absence of association between sex and body position, rhythm of transition or technique executed suggests that male and female athletes have a similar behavior during the transitions resulting in scores in the groundwork combat. The only difference between these groups was concerning the moment of the match when these scores occurred, with females scoring earlier during the match compared to males. The reason for this difference is hard to explain, but it has been reported that female athletes start to recruit the oxidative system faster during high-intensity intermittent exercise (Billaut \& Bishop, 2009). Indeed, the reliance on oxidative sources results in a decrease in effort intensity, which would result in a higher vulnerability during groundwork combat. Indeed, this can also explain why males used more frequently immediate transition than females, as it is reasonable to assume that progressive transition attacks demand more anaerobic capacity than immediate transitions. Indeed, another study also reported that groundwork combat time was longer in male matches compared to female matches (Sterkowicz-Przybycien, Miarka, \& Fukuda, 2017). Possibly, female are more efficient than male judo athletes. In fact, a recent study (Kons, Franchini, \& Detanico, 2018) demonstrated that effectiveness was higher in females compared to males in longer-duration official judo matches (defined in the study as matches longer than $2 \mathrm{~min}$ ). The same study also demonstrated that effectiveness in shorter than 2-min female matches was positively correlated $(\mathrm{r}=0.56)$ with total number of throws during the Special Judo Fitness Test, suggesting that female judo athletes with higher anaerobic capacity would be more efficient in official matches..

Moreover, there were no significant associations between age and body position, and between age and match status, suggesting that junior and senior judo athletes present the same behavior during this combat phase. This is likely due to the fact that athletes in the junior 
group are already sexually mature and physiologically similar to seniors (Franchini et al., 2011). In tachi-waza, previous studies also reported that the variation of direction of attacks was similar between junior and senior judo athletes (Calmet et al., 2004). Thus, it seems that the technical-tactical base of judo athletes is determined when they are juniors, especially for those achieving international level as those analyzed in the present study. Moreover, no associations were found between competition phase and body position, rhythm of transition, type of techniques, or status of the match. This is supported by Roux (1990) who reported that transitions occur in accordance with the development of the fight, which is by its nature random.

In conclusion, the transition scoring actions occurred when an immediate link between standing and groundwork actions almost half of the occurrences, osae-komi-waza was predominantly used $(\sim 75 \%)$, and these actions were executed mainly when the match was tied ( $71 \%)$. Additionally, females scored earlier during the match compared to males when using these actions. However, no associations were found between sex and body position, rhythm of transition or technique, between age and body position, and between age and match status or between competition phase and body position, rhythm of transition, type of techniques, or status of the match.

\section{Disclosure statement}

The authors declare that there is no conflict of interest.

\section{References}

Adam M., Smaruj M, Tyszkowski S. (2011), The diagnosis of the technical-tactical preparation of judo competitiors during the World Championships (2009-2010) in the light of the new judo sport rules, "Archives of Budo", vol. 7, no. 1, pp. 5-9.

Balafoutas, L., Lindner, F., \& Sutter, M. (2013). Sabotage in tournaments: Evidence from a natural experiment. Kylos, 65, 425-441.

Billaut, F., \& Bishop, D. (2009). Muscle fatigue in males and females during multiple-sprint exercise. Sports Medicine, 39, 257-278.

Calmet M., Ahmaidi S. (2004), Survey of advantages obtained by judoka in competition by level of practice, "Perceptual and Motor Skills" vol. 99, no. 1, 284-290. 
Calmet M., Trezel N., Ahmaidi S. (2006), Survey of system of attack by judoka in regional and interregional matches, "Perceptual and Motor Skills", vol. 103, no. 3, pp. 835-840.

Calmet M., Miarka B., Franchini E. (2010), Modeling of grasps in judo contests, "International Journal of Performance Analysis in Sport", vol. 10, no. 3, pp. 229-240.

Calmet, M. Pierantozzi, E. Sterkowicz, S., Challis, B., Franchini, E. (2017a). Rule change and Olympic judo scores, penalties and match duration, International Journal of Performance Analysis in Sport, 17(4), 458-465.

Calmet, M. Pierantozzi, E. Sterkowicz, S., Takito, MY., Franchini, E. (2017b). Judo rules: searching for a wind of changes, International Journal of Performance Analysis in Sport, 17(6), 863-871.

Castarlenas, J.L., \& Planas, A. (1997) Estudio de la estructura temporal del combate de judo. Apunts - Educação Física \& Deportes.47: 32-39

Courel J., Femia O., Stankovic N., Franchini E., Escobar-Molina R. (2014), Analysis of kumikata grip laterality and throwing side on attack effectiveness and combat result in elite judokas, "International Journal of Performance Analysis in Sport", vol. 14, no. 1, pp. 138147.

Escobar-Molina R., Courel J., Franchini E., Femia O., Stankovic N. (2014), The impact of penalties on subsequent attack effectiveness and combat outcome among high elite judo competitors, "International Journal of Performance Analysis in Sport", vol. 14, no. 3, pp. 946-954.

Franchini E., Sterkowicz S., Meira C.M., Gomes F.R., Tani G. (2008), Technical variation in a sample of high level judo players, "Perceptual and Motor Skills", vol. 106, no. 3, pp. 859-869.

Franchini, E. Del, Vecchio, F. B., Matsushigue, K. A., \& Artioli, G. G. (2011). Physiological profiles of elite judo athletes. Sports Medicine, 41(2), 147-166.

Kashiwazaki, K. (2004). Osaekomi: judo masterclass techniques. London: Ippon Books.

Kons, Franchini, Detanico 2018

International Judo Federation (2018, November 16). IJF Rules 2017-2020. Retrieved from: http://www.ijf.org

Marcon, G., Franchini, E., Jardim, J. R., \& Neto, T. L. B. (2010). Structural analysis of action and time in sports: Judo. Journal of Quantitative Analysis in Sports, 6(4), 1-15.

Miarka, B., Hayashida, C. R., Julio, U. F., Calmet, M., \& Franchini, E. (2011). Objectivity of FRAMI-software for judo match analysis. International Journal of Performance Analysis in Sport, 11(2), 254-266.

Miarka, B., Branco, B.H.M., Vecchio, F.B., Camey, S., \& Franchini, E. (2015). Development and validation of a time-motion judo combat model based on the Markovian processes. International Journal of Performance Analysis in Sport, 15(1), 315-331.

Pierantozzi, Emanuela; Calmet, Michel; Franchini, Emerson. The transition to Ne Waza in a sample of high level Judo competition. 3rd European Science of Judo Research Symposium \& 2nd Scientific and Professional Conference on Judo: "Applicable research in Judo"; June 2016; Poreč, Croatia. Samobor: Faculty of Kinesiology, University of Zagreb, Croata; 2016.

Pierantozzi, E., Calmet, C., Franchini, E. Successful transitions to newaza in a sample of high level judo competition. 4th European Science of Judo Research Symposium \& 3rd Scientific and Professional Conference on Judo: “Applicable research in Judo"; June 2017; Poreč, Croatia. Samobor: Faculty of Kinesiology, University of Zagreb, Croata; 2017.

Roux P. (1990) Contribution à l'analyse de la transition : combat debout-combat au sol. Paris, INSEP, 1990

Sterkowicz-Przybycien, K., Miarka, B., \& Fukuda, D. H. (2017). Sex and weight category 
differences in time-motion analysis of elite judo athletes: Implications for assessment and training. Journal of Strength and Conditioning Research, 31, 817-825.

Weers, G. (1996). Transitional control. Available from: http://www.judoinfo.com/weers4.htm [8 dec. 1996]

Weers, G. (1997). Newaza preparation report. Available from:

http://www.judoinfo/weers96.htm [16 nov. 1997] 